\title{
Thermal Analysis of Magnetic Nanoparticles Modified with Dextran
}

\author{
A. Juríková, K. Csach, J. Miškuf, M. Koneracká, V. Závišová, M. KubovČíková \\ AND P. KOPČANSKÝ
}

Institute of Experimental Physics, Slovak Academy of Sciences, Watsonova 47, 04001 Košice, Slovakia

\begin{abstract}
In the work the thermal behaviour of the magnetic nanoparticles modified with polysaccharide dextran of different weight ratios to the magnetite $\mathrm{Fe}_{3} \mathrm{O}_{4}$ was investigated using thermoanalytical methods - differential scanning calorimetry and thermogravimetric analysis. The adsorption of dextran on the magnetic nanoparticles was confirmed and the influence of the dextran amount in the modified magnetic fluid on the thermal decomposition of the complex system was studied. The results showed that magnetite catalyzed the thermal decomposition of dextran, the adsorbed dextran showed lower initial decomposition temperatures in comparison with the free one.
\end{abstract}

PACS: 47.65. Cb, 65.80.-g

\section{Introduction}

Magnetic nanoparticles dispersed in different liquid carrier solutions (colloidal suspensions) have been very attractive recently, because of their unique magnetic properties and fluidity. They have a wide range of technical and biomedical applications $[1,2]$ such as magnetic separation, targeted drug delivery etc. They can be used as therapeutical agents against wide range of tumours (breast cancer, ovarian carcinoma, lung cancer, head and neck carcinomas) and amyloid diseases (Alzheimer's and Parkinson's diseases and type II diabetes mellitus) associated with presence of amyloid aggregates in various parts of the body.

The stability of the iron oxide based magnetic nanoparticles used in biomedicine is greatly improved by the addition of a suitable biocompatible substance without causing any allergic or rejective reactions in the human body. To produce such biocompatible surfaces, it is necessary to form a permanent chemical bond between magnetic particle surface and the biocompatible material. Polyethylene glycol, polysaccharide dextran, protein bovine serum albumin or poly (D,L-lactide-co-glycolide) polymer are the most used biocompatible agents for the modification of the magnetic nanoparticles [3-7]. In the present work we used dextran for modification of sodium oleate coated magnetic nanoparticles. Dextran is a polymer $\left(\mathrm{C}_{6} \mathrm{H}_{10} \mathrm{O}_{5}\right)_{n}$ that interacts with metals in aqueous solutions and covers its surface. The thermal analysis (differential scanning calorimetry (DSC) and thermogravimetric analysis (TGA)) of the biocompatible complex system with different feed weight ratios of dextran to magnetite $\mathrm{Fe}_{3} \mathrm{O}_{4}$ was performed with the aim to confirm the adsorption of dextran on magnetic nanoparticle surfaces and to determine the influence of the dextran concentration on the stability and the thermal decomposition of the complex biocompatible system.

\section{Experimental}

Typically ferric chloride hexahydrate $\left(\mathrm{FeCl}_{3} \cdot 6 \mathrm{H}_{2} \mathrm{O}\right)$, ferrous sulphate heptahydrate $\left(\mathrm{FeSO}_{4} \cdot 7 \mathrm{H}_{2} \mathrm{O}\right)$ and ammonium hydroxide $\left(\mathrm{NH}_{4} \mathrm{OH}\right)$ were used for magnetite synthesis. Sodium oleate was obtained from Riedel-de Haën, polysaccharide polymer dextran and all other chemicals were obtained from the Sigma-Aldrich.

The co-precipitation method of ferric and ferrous salts in an alkali aqueous medium was used to prepare spherical magnetite particles [8]. In a typical synthesis, aqueous solution of $\mathrm{Fe}^{3+}$ and $\mathrm{Fe}^{2+}$ in a molar ratio $2: 1$ was prepared by dissolving in deionised water. To this mixture of $\mathrm{Fe}^{3+}$ and $\mathrm{Fe}^{2+}$, an excess of hydroxide ions was added at room temperature, under vigorous stirring. After washing the precipitate of magnetite nanoparticles by magnetic decantation and heating up to $50^{\circ} \mathrm{C}$, the surfactant sodium oleate $\left(\mathrm{C}_{17} \mathrm{H}_{33} \mathrm{COONa}\right.$, theoretical ratio $0.7 \mathrm{~g}$ to $1 \mathrm{~g}$ of $\mathrm{Fe}_{3} \mathrm{O}_{4}$ ) was added to the mixture to prevent the agglomeration of the particles. This mixture was stirred under heating until the boiling point was reached. Magnetite particles stabilized by oleate bilayer were dispersed in water. Agglomerates were removed by centrifugation for $30 \mathrm{~min}$. The system at this stage is denoted below as the initial magnetic fluid (MF). Finally, polysaccharide polymer dextran (DEX) with a molecular weight approximately of $64 \mathrm{kDa}$ was added to the initial magnetic fluid $\mathrm{MF}$ in weight ratios of dextran $/ \mathrm{Fe}_{3} \mathrm{O}_{4}$ varying from 0.25 to 2.5 at the temperature of $50^{\circ} \mathrm{C}$. The mixture was stirred for half an hour. In this way, the magnetic fluid 
containing magnetic nanoparticles coated with sodium oleate and dextran (MFDEX) was formed.

The thermal properties of the prepared biocompatible magnetic fluid after the lyophilization were characterized by DSC and TGA methods. DSC measurements were performed using Perkin Elmer DSC7 calorimeter at the rate of $10^{\circ} \mathrm{C} / \mathrm{min}$ up to the temperatures of $450^{\circ} \mathrm{C}$ in the flowing nitrogen atmosphere and TGA was carried out using a SETARAM thermobalance model TGDTA92 at the heating rate of $10^{\circ} \mathrm{C} / \mathrm{min}$ in the temperature range of 25 to $700{ }^{\circ} \mathrm{C}$ in the argon atmosphere.

\section{Results and discussion}

Biocompatible magnetic fluids based on iron oxide $\left(\mathrm{Fe}_{3} \mathrm{O}_{4}\right)$ particles stabilized by sodium oleate and modified with dextran of different feed amounts, were prepared and characterized. Their magnetic properties and the structure were studied in the previous papers $[9,10]$ where their superparamagnetic behaviour at the room temperature was confirmed. The mean hydrodynamic diameter for MKDEX particles with DEX to magnetite ratio of 0.5 was found to be $65 \mathrm{~nm}$ and the magnetic diameter of the particles was $10 \mathrm{~nm}$.

DSC measurements for pure dextran and lyophilized MF, for the physical mixture of pure dextran and lyophilized MF and for MFDEX with different DEX to magnetite feed weight ratios $x$ (varying from 0.5 to 2.5 ) were carried out. The typical DSC traces can be seen in Fig. 1. In the case of pure dextran, the broad endothermic peak starting at $50{ }^{\circ} \mathrm{C}$ was ascribed to the water evolving [11]. At temperatures higher than $270^{\circ} \mathrm{C}$, the breakdown of the organic skeleton of dextran took place. The initial MF, i.e. magnetic nanoparticles without dextran modifying, shows three only slight endotherms that can be associated with impurities in the initial magnetic fluid. In the case of the physical mixture of pure dextran and lyophilized MF where dextran is not adsorbed on the magnetic nanoparticles, only the simple superposition of the pure dextran and initial MF traces is observed. In the case of MFDEX, where dextran is adsorbed on magnetic nanoparticles, the onset of the dextran decomposition was shifted to the temperatures of up to $50^{\circ} \mathrm{C}$ lower.

The results of thermogravimetric measurements are shown in Figs. 2 and 3. Figure 2 shows typical thermal decomposition curves of MFDEX, i.e. dextran-modified magnetic nanoparticles with different feed ratio DEX to magnetite. The curves of pure MF and dextran components are added for comparison.

Corresponding derivative TG curves can be seen in Fig. 3. During heating up to the temperature of $600^{\circ} \mathrm{C}$, the dried initial magnetic fluid MF shows one significant decomposition stage starting at about $300{ }^{\circ} \mathrm{C}$ that is connected with the evaporation of sodium oleate used for the stabilization of the magnetic nanoparticles. The total mass loss up to $600{ }^{\circ} \mathrm{C}$ was $34 \%$. The thermal decomposition of free dextran occurs through two good distinguished stages.

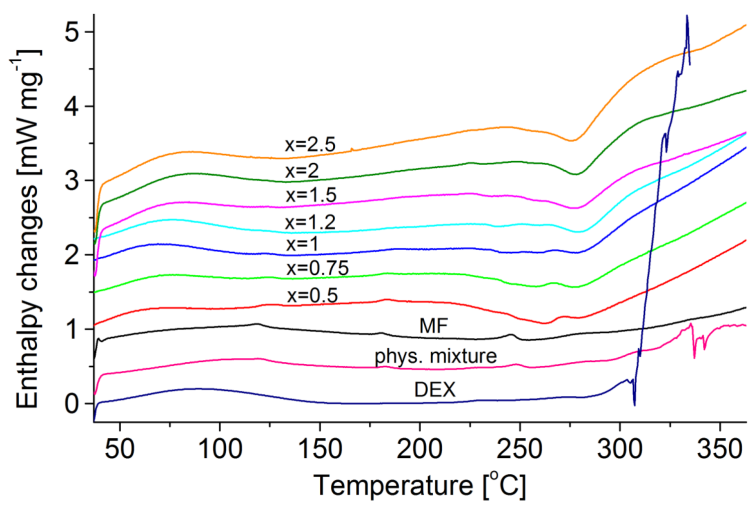

Fig. 1. DSC traces of pure dextran, magnetic fluid without dextran (MF), physical mixture of MF and dextran and DEX-modified magnetic fluid MFDEX with different dextran to magnetite weight ratios.

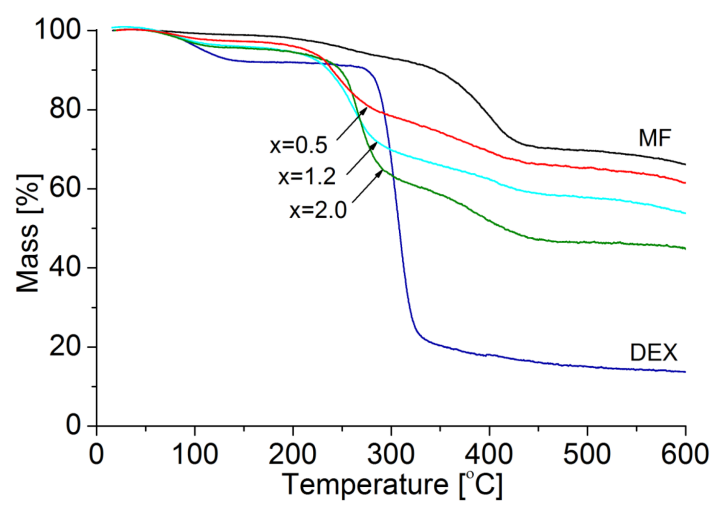

Fig. 2. Thermal decomposition traces of pure dextran, magnetic fluid without dextran (MF) and dextran-modified magnetic fluid MFDEX with different dextran to magnetite weight ratios.

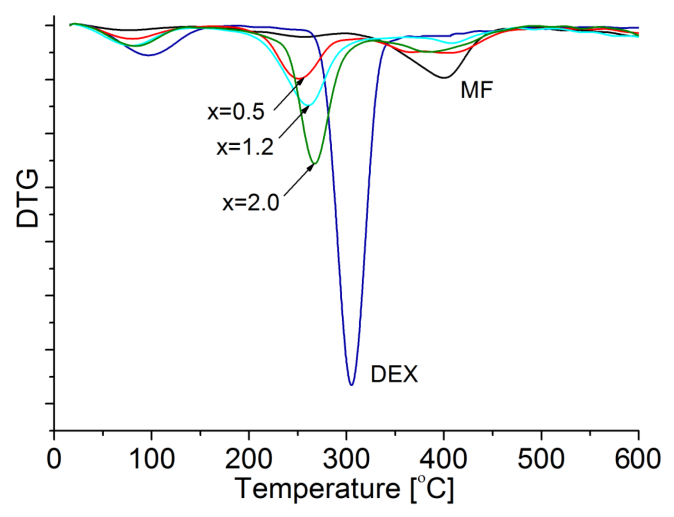

Fig. 3. Derivative thermogravimetric curves of pure dextran, magnetic fluid without dextran (MF) and dextran-modified magnetic fluid MFDEX with different dextran to magnetite weight ratios. 
The first decomposition stage in the temperature range from 20 to $150^{\circ} \mathrm{C}$ represents the water evolving (mass loss $8 \%$ ). The second one in the temperature range of 250 $350{ }^{\circ} \mathrm{C}$ with mass loss of $80 \%$ corresponds to the organic breakdown of polysaccharide dextran chains, the total mass loss up to $600{ }^{\circ} \mathrm{C}$ was $86 \%$. The thermal decomposition of dried dextran-modified magnetite nanoparticles with chosen feed amounts of dextran to magnetite $x=0.5,1.2$ and 2.0 occurs through three stages. The first two stages are related to the thermal decomposition of dextran, whereas the last one with the decomposition of sodium oleate coating magnetic nanoparticles, and does not depend on the amount of dextran added to the MF.

However, dextran adsorbed on the magnetic nanoparticles surface decomposes at lower temperatures than free dextran. The starting of the organic skeleton breakdown occurs at temperature of about $50^{\circ} \mathrm{C}$ lower. These results are in accordance to DSC measurements mentioned above. It can be said that the magnetite nanoparticles catalyze the thermal decomposition of dextran.

A catalytic effect of magnetite towards the degradation of organic coating has already been reported in the literature [11]. The maximal temperature of the main decomposition peak increases with the increasing DEX $/ \mathrm{Fe}_{3} \mathrm{O}_{4}$ ratio, whereas start and end temperatures of the decomposition stage are not changed, they are in the range of $200-330^{\circ} \mathrm{C}$. Total mass losses up to the temperature of $600{ }^{\circ} \mathrm{C}$ for the samples of MFDEX with DEX to magnetite ratios of $0.5,1.2$ and 2.0 were 38,46 , and $55 \%$, respectively. Derivative TG curves in Fig. 3 show the uniformity of the decomposition of the complex system with dextran-modified magnetite nanoparticles.

\section{Conclusion}

Biocompatible magnetic fluid modified with dextran was successfully prepared and thermally characterized. DSC and TG analyses confirmed the adsorption of dextran on sodium oleate coated magnetic nanoparticles and the stability of the complex system. Catalytic effect of the magnetite towards the degradation of dextran was observed. The obtained results make dextran-modified magnetic fluids of potential interest as the therapeutic agents effective in medical purposes.

\section{Acknowledgments}

This work was supported by implementation of the projects Nos. 26220120021 and 26220120033 provided by the European Regional Development Fund. The authors are also grateful to the Slovak Academy of Sciences the Centre of Excellence "Nanofluid", VEGA No. 0185/11 and Slovak Research and Development Agency - contract No. APVV-0171-10.

\section{References}

[1] Q.A. Pankhurst, N.K.T. Thanh, S.K. Jones, J. Dobson, J. Phys. D, Appl. Phys. 42, 224001 (2009).

[2] H. LeVine, Curr. Med. Chem. 9, 1121 (2002).

[3] D.Q.M. Craig, Thermochim. Acta 248, 189 (1995).

[4] M.V. Avdeev, A.V. Feoktystov, P. Kopcansky, G. Lancz, V.M. Garamus, R. Willumeit, M. Timko, M. Koneracka, V. Zavisova, N. Tomasovicova, A. Jurikova, K. Csach, L.A. Bulavin, J. Appl. Crystallogr. 43, 959 (2010).

[5] M.C. Bautista, O.B. Miguel, M. del P. Morales, C.J. Serna, S.V. Versaguer, J. Magn. Magn. Mater. 293, 20 (2005).

[6] Z.G. Peng, K. Hidajat, M.S. Uddin, Colloids Surf. B 33, 15 (2004).

[7] A. Juríková, K. Csach, J. Miškuf, M. Koneracká, V. Závišová, P. Kopčanský, Acta Phys. Pol. A 118, 990 (2010).

[8] H. Fessi, F. Puisieux, J.P. Devissaguet, N. Ammoury, S. Benita, Int. J. Pharm. 55, R1 (1989).

[9] A. Antošová, M. Koneracká, K. Šipošová, V. Závišová, Z. Daxnerová, I. Vavra, M. Fabian, P. Kopčanský, Z. Gažová, AIP Conf. Proc. 1311, 317 (2010).

[10] M. Koneracká, A. Antošová, V. Závišová, G. Lancz, Z. Gažová, K. Šipošová, A. Juríková, K. Csach, J. Kováč, N. Tomašovičová, M. Fabián, P. Kopčanský, Acta Phys. Pol. A 118, 983 (2010).

[11] O. Carp, L. Patron, D.C. Culita, P. Budrugeac, M. Feder, L. Diamandescu, J. Therm. Anal. Calorim. 101, 181 (2010). 